TPeriodica Polytechnica Civil Engineering

OnlineFirst (2018) paper 11974

https://doi.org/10.3311/PPci.11974

Creative Commons Attribution (i)

\section{A Study on the Relationship Between Matric Suction and the Void Ratio and Moisture Content of a Compacted Unsaturated Soil}

\author{
Minh The Kieu ${ }^{1,2^{*}}$, András Mahler ${ }^{1}$
}

Received 18 January 2018; Revised 25 January 2018; Accepted 29 January 2018

\begin{abstract}
The volumetric behaviour of compacted unsaturated soils is particularly complex due to the co-existence of three different phases: solid, liquid and air. Matric suction has been perceived as a significant influence on the volumetric behaviour of unsaturated soils and has been used as one of the constitutive variables for most the constitutive models of unsaturated soils in the literature. However, suction-controlled works are complex in practice since they generally require special test procedures and advanced equipment, and usually are very time-consuming. Thus, some researchers have tried to seek alternative frameworks that use the traditional choice of state variables to simulate the behaviour of unsaturated soils. Recently, Kodikara [1] proposed the MPK framework to interpret the behaviour of compacted unsaturated soil in the void ratio (e) - net stress $(p)$ - moisture ratio $\left(e_{w}\right)$ space. The distinct advantage of the model is that it is based on traditional constant moisture content compaction testing which is more common and simple than constant suction loading. The MPK framework has been shown to be capable of presenting the volumetric behaviour of compacted unsaturated soils. However, this framework is expected to use not only for compacted soil but for the behaviour of unsaturated soil in general. The incorporation of soil suction within the MPK framework can be helpful for creating a correlation with previous models which used matric suction as a constitutive variable. This paper presents the development of LWSBS for one clayey soil in Hungary within the MPK framework and then suction is incorporated, which is related to void ratio and moisture ratio through SWCC.
\end{abstract}

\footnotetext{
Keywords

unsaturated soil, compacted soil, MPK framework, soil suction

1 Department of Engineering Geology and Geotechnics

Faculty of Civil Engineering,

Budapest University of Technology and Economics

1111 Budapest, Mủegyetem rkp. 1., Kf 10.

2 Faculty of Civil Engineering,

Thuyloi University, 175 Tay Son, Dong Da, Hanoi, Vietnam

*Corresponding author, email: correspondingauthor@mail.bme.hu
}

\section{Introduction}

Compacted unsaturated soils are widely used in geotechnical and geo-environmental works such as earth dams, road embankments, retaining walls, foundations, and waste covers. Unlike saturated soils, an unsaturated soil can undergo significant volume change upon changing of the degree of saturation. The volumetric behaviour of compacted unsaturated soils is particularly complex due to the co-existence of three different phases: solid, liquid and air. The modelling of the hydromechanical behaviour of unsaturated soils is a frontier in soil mechanics research [1].

Over the past few decades, numerous studies have been performed concerning the volumetric behaviour of unsaturated soils. A general constitute model of unsaturated soil behaviour was first proposed by Alonso et al. [2], using the framework of independent stress state variables (i.e. net stress and suction). This approach was followed and modified by many other researchers [3][4][5][6][7][8][9]. Gallipoli et al. [6] introduced the use of the degree of saturation, which has a direct relationship with the void ratio, the applied stress, and the soil-water characteristic curve (SWCC), as one of soil constitutive variables to present the effects of soil suction. It is well accepted that matric suction has a significant influence on the volumetric behaviour of unsaturated soils. Matric suction was used as one of the constitutive variables for most the constitutive models of unsaturated soils in the literature. However, suction-controlled works are complex in practice since they generally require special test procedures and advanced equipment, and usually are very time-consuming. Thus, some researchers have tried to seek alternative frameworks that use the traditional choice of state variables to simulate the behaviour of unsaturated soils.

Kodikara [1] proposed the MPK framework to interpret the behaviour of compacted unsaturated soil in the void ratio $(e)$ - net stress $(p)$ - moisture ratio $\left(e_{w}\right)$ space. Soil suction is presented as the fourth variable and is related to void ratio and moisture ratio through SWCC. Kodikara [1] and Islam [10] have analysed many data in the literature within the MPK framework and proven that the volumetric behaviour of compacted unsaturated soils can be well explained by using $e, p$, and $e_{w}$ variables. However, MPK framework is expected to 
use not only for compacted soil but also for the behaviour of unsaturated soil in general. The incorporation of soil suction within the MPK framework can be helpful for creating a correlation with the previous models that used matric suction as a constitutive variable. This paper presents the development of LWSBS for one clayey soil in Hungary within the MPK framework and then suction is incorporated, which is related to void ratio and moisture ratio through SWCC.

\section{Background}

\subsection{Effective stress approach for modelling behaviour of unsaturated soil}

As summarized by Sheng [11], there are three approaches for modelling behaviour of unsaturated soil: two independent state variables (i.e. net stress $p=\sigma-u_{a}$ and suction $s=u_{a}$ $-u_{w}$ ) approach, combined stress-suction approach, and SFG approach - which is a middle ground between the first two approaches. Combined stress-suction approach or the effective stress approach uses an effective or skeleton stress as a combination of net stress and suction. In this approach, the virgin compression behaviour is generally presented as:

$$
v=N-\lambda \ln \left(p^{\prime}\right)
$$

where $v=1+e$ is the specific volume; $N$ is the specific volume when $\ln \left(p^{\prime}\right)=0 ; \lambda$ is the slope of the $v-\ln p^{\prime}$ line; $e$ is void ratio; effective stress $p^{\prime}=\left(\sigma-u_{a}\right)+\chi\left(u_{a}-u_{w}\right)$ was proposed by Bishop [12] modifying Terzaghi's classical effective stress theory for unsaturated soils; $\chi$ is a parameter dependent on the degree of saturation $S_{r}$.

Kodikara [1] highlighted that, even with the definition of an effective stress, there exists a state boundary surface (SBS) for virgin compression that both $N$ and $\lambda$ can still be functions of suction. Gallipoli et al. [6] suggested that both $N$ and $\lambda$ are functions of not only suction, but also of the degree of saturation $\left(S_{r}\right)$ and provided the following relationship:

$$
v=\left(N-\lambda \ln p^{\prime}\right)[1-a(1-\exp (b \xi))]
$$

where $N$ and $\lambda$ are the two parameters of the normal compression line for saturated states, a and $\mathrm{b}$ are fitting parameters, the effective stress $p^{\prime}$ is defined as $p+S_{r} s$, and $\xi$ is a positive variable representing bonding effects due to suction.

\subsection{MPK framework}

The main concept of the MPK framework is that it presents the Loading Wetting State Boundary Surface (LWSBS) in $e-e_{w}-p$ space. Fig. 1 shows the three-dimensional view of the LWSBS in $e-e_{w}-p$ space, introduced by Kodikara [1]. As mentioned by Kodikara [1], void ratio is chosen because it is more familiar to the general geotechnical community. The use of moisture ratio $\left(e_{w}=w G_{s}\right.$, where $w$ is the gravimetric moisture content and $G_{s}$ is the specific gravity of soil) with void ratio will lessen the influences of hysteresis in soil suction during wetting and drying because both parameters display significant hysteresis with suction and this effect can be eliminated when they are taken into account together. The LWSBS is developed by combining compaction curves at different initial moisture ratios, presenting the upper surface for the volumetric behaviour of soil where loading and wetting paths are located. As shown in Fig. 1, the Line of Optimum (LOO) is determined on the LWSBS by connecting the optima of different compaction curves. The LOO divides the LWSBS into two parts involving the dry side of LOO where air phase is perceived to be continuous and freely drain during loading (or wetting), and the wet side of LOO which is built by the drained section of compaction curves between the LOO and the Normal Consolidation Line (NCL).

The MPK framework has been examined by Kodikara [1] using some reported experimental data in the literature. This framework was also used in Islam's [10] study to interpret the loading/wetting behaviour of compacted soils. The distinct advantage is that the model is based on traditional constant moisture content compaction testing which is more common and simple than constant suction loading.

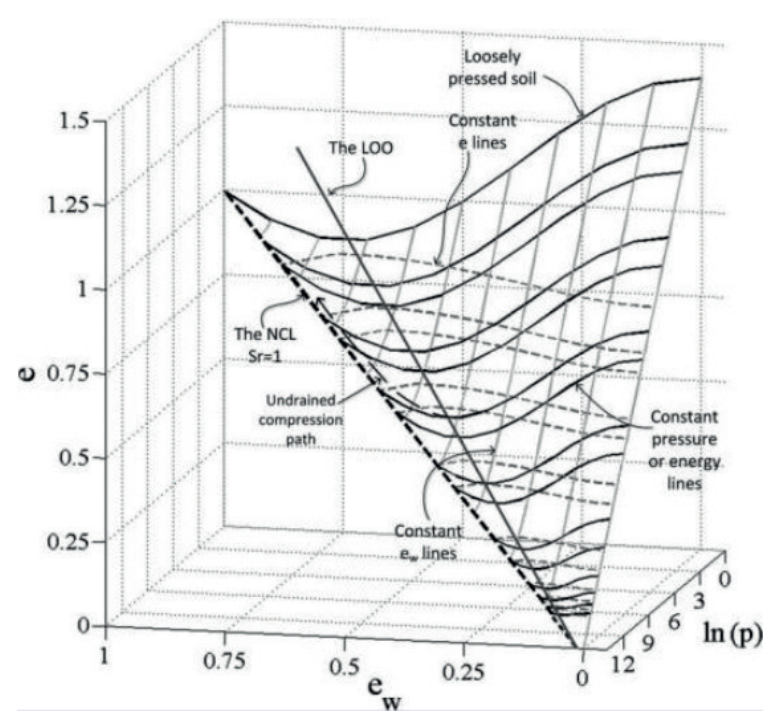

Fig. 1 LWSBS in $e-p-e_{w}$ space [1]

Table 1 Properties of the soil used in the study

\begin{tabular}{lc}
\hline Properties & Values \\
\hline Liquid limit, W1 (\%) & 52.2 \\
Plastic limit, Wp (\%) & 24.05 \\
Plastic index, Ip (\%) & 28.15 \\
Shrinkage limit (\%) & 20.14 \\
Specific gravity, Gs & 2.72 \\
Clay content (<0.002 mm, \%) & 24 \\
Smectite group content (\%) & 16 \\
$\quad$ Kaolinite content (\%) & 2 \\
Illite - hydromica group content (\%) & 6 \\
Silt content (\%) & 71 \\
Fine sand content $(\%)$ & 5 \\
\hline
\end{tabular}




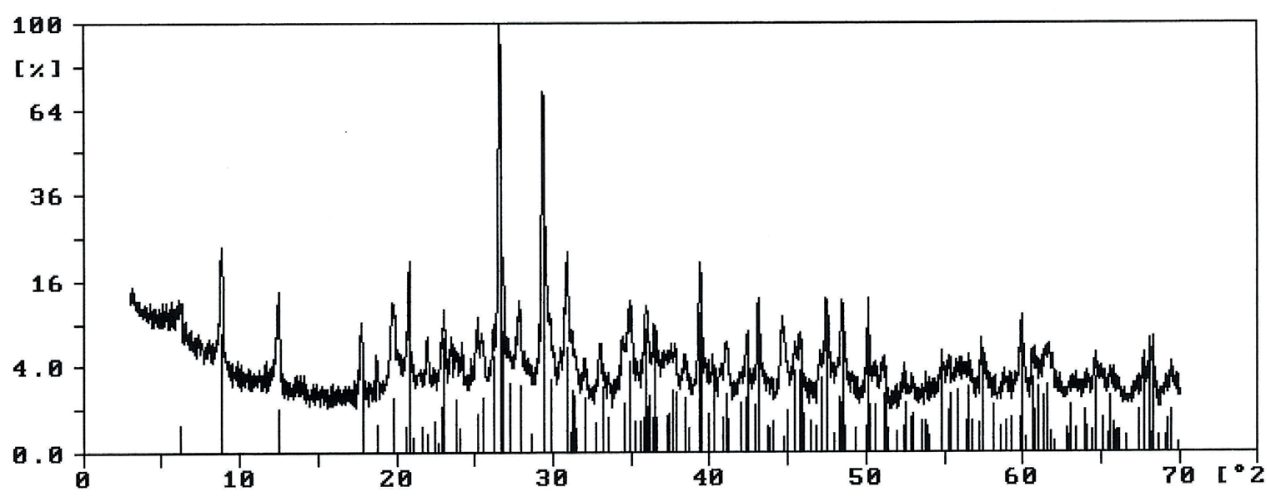

Fig. 2 X-ray diffraction patterns of the soil used in the study

\section{Soil used and methods}

\subsection{Soil used}

A type of soil from the Oligocene "Kiscelli" clay formation was studied. The soil samples, collected from the extension of the M0 Highway project near Budapest, Hungary, was used throughout the experimental work. The natural soil was processed to be finer than $425 \mu \mathrm{m}$ with the liquid limit and plastic limit are 52.2 and $24.05 \%$, respectively. The properties of the soil used are shown in Table 1.

X-ray diffraction analysis of the soil (Fig. 2) shows the existence of smectite group, indicating that the soil has absorption capacity. This property is also found in other soils in Hungary [13]. Thermoanalytical analyses (TG/DTA) were carried out by the Geotechnical Laboratory at Budapest University of Technology and Economics showed several phases of minerals, which are presented in Table 1.

\subsection{Methods}

The soil used was processed to be finer than $425 \mu \mathrm{m}$ and then were air-dried at room conditions to the moisture contents of $1.56 \%$. Soil samples were prepared using air-dried soil mixed with predetermined amounts of water to have moisture contents in the range of 1.56 to $44 \%$. The mixes were placed in sealed plastic bags for at least 3 days.

The soil was statically compacted in an oedometer mould of $75 \mathrm{~mm}$ internal diameter and $40 \mathrm{~mm}$ height. Two filter papers were placed at the bottom of the mould and between the soil and the loading pad allowing drainage (both air and water) from the soil sample. In order to reduce the influence of friction between soil and mould, lubricating grease was applied on the wall of the mould. At each value of moisture content six duplicated soil samples were compressed by a given vertical stress $(100,200$, $300,600,1200$ or $1800 \mathrm{kPa}$ ) at loading rates varying from 20 to $50 \mathrm{kPa} / \mathrm{min}$ (higher rate for larger value of compression) for the sample at the dry side of optimum. As highlighted by Tarantino and $\mathrm{De} \mathrm{Col}[8]$ that at a loading rate of $5 \mathrm{kPa} / \mathrm{min}$ matric suction in soil sample did not exhibit discontinuities, in this study the loading rate was slowed down to $5 \mathrm{kPa}$ per min when the state path close to the LOO (when $S_{r}>80 \%$ ). This treatment is necessary to make sure water can run out of soil samples during drained path and air pressure will not build up in samples. Each applied vertical pressure was maintained constant for $10 \mathrm{~min}$, after that one sample was unloaded, and used to determine moisture content and dry density. One more duplicated sample was subjected to loading-unloading (to $15 \mathrm{kPa}$ ) cycles to 100 , 200, 300, 600, 1200 and $1800 \mathrm{kPa}$ (loading points were fewer for the samples having higher moisture content). The results from compaction process at different moisture contents were used to generate the LWSBS of the soil.

\section{Results and Discussion \\ 4.1 Development of the LWSBS}

Compaction experiment was conducted at thirteen different moisture contents $(1.56,3.56,6.73,11.95,13.16,18.22,20.19$, $22.49,24.55,26.84,28.89,30.92$, and $33 \%$ ). The applied stress varied from nominal stress $(15 \mathrm{kPa})$ to $1800 \mathrm{kPa}$. The moisture contents and the dry densities of soil samples were determined at the applied stress of 100, 200, 300, 600, 1200, and $1800 \mathrm{kPa}$. By using this method, the soil properties were captured during drained paths. The compression curve in term of the traditional relationship between the void ratio and vertical stress $(p)$ at $24.55 \%$ initial moisture content $\left(e_{w}=0.668\right)$ is shown in Fig. 3. Fig. 4 presents the compression curve at some different moisture contents on $e-\log (p)$ plane. A number of tests were repeated under the same conditions indicating that the results are well reproducible.

It is clear in Fig. 3b that the measured moisture contents of the points at the dry side of the line of optimum (LOO) are identical and equal to the initial water content, meaning that water was maintained in the sample at those points; the compressibility coefficient is constant during loading. As highlighted by Tarantino and De Col [8], it can be assumed that the air phase is mainly continuous and is freely drained out of the samples, and the net stress is equal to the vertical stress. This trend was found in the other curves, as shown in Fig. 4. It can also be seen in Fig. 4 that, the compressibility $(\lambda)$ increases with increasing the initial moisture content. As for the points on the wet side of the LOO, measured moisture contents decrease with increasing vertical stress, indicating that water was drained out before the soil specimen reached to the saturation line. During the draining 
process, the compression curves head toward the saturated Normal consolidation line (NCL). As mentioned in the method section, the loading rate was slowed down when the soil specimens approached close to the LOO, and each recording stress was maintained for 10 min allowing the air and water inside the specimens reach equilibrium, and then it also can be assumed that the net stress is equal to the vertical stress in this case.

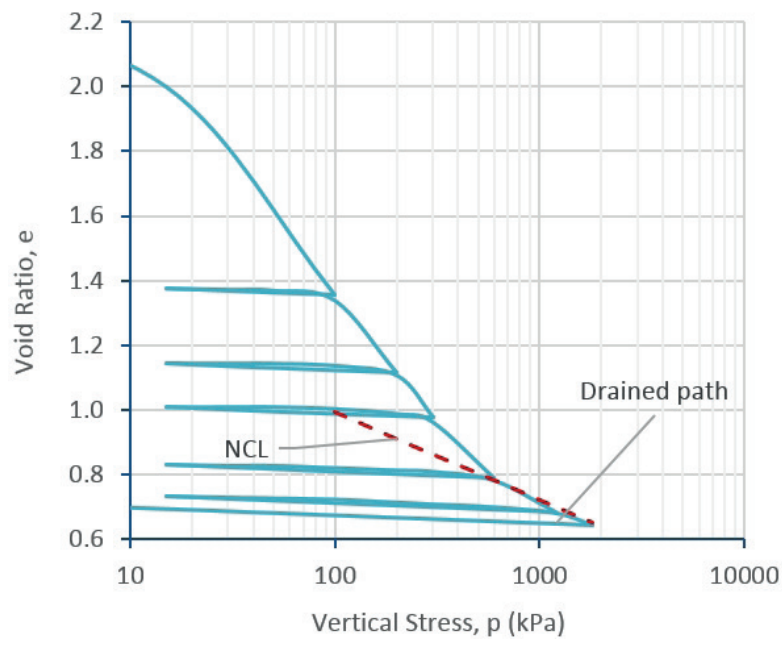

(a)

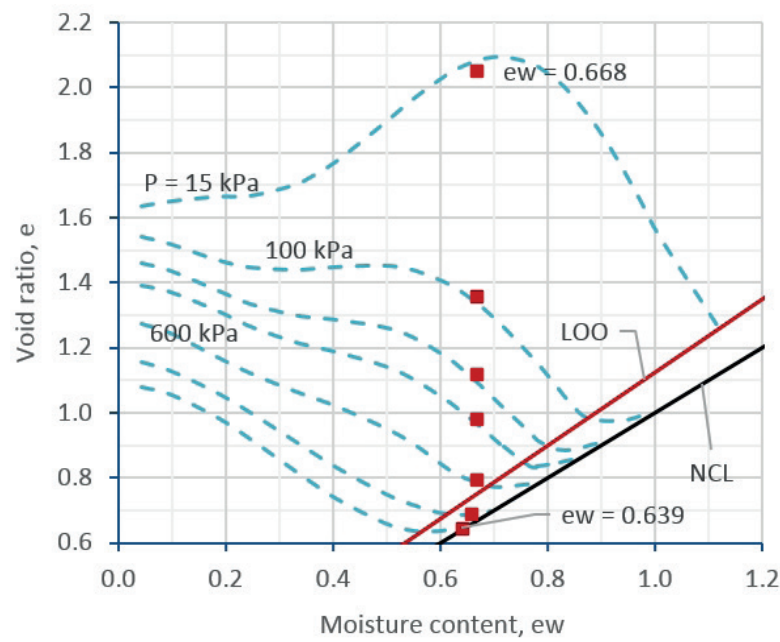

(b)

Fig. 3 Compression curve at $24.55 \%$ initial moisture content $\left(e_{w}=0.668\right)$ : (a) in the $e-\ln (p)$ plane; $(b)$ in $e-e_{w}$ plane

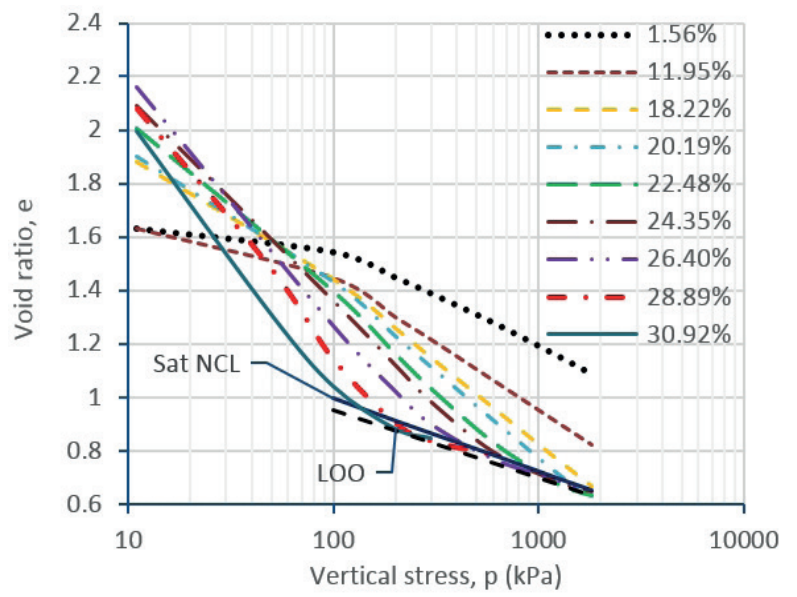

Fig. 4 Compression curves at some different moisture contents

\subsection{Incorporation of suction on the LWSBS}

The relationship between soil suction and the void ratio and the moisture ratio of soil on the LWSBS was developed separately on the two parts of the LWSBS, the wet side and the dry side of the LOO. As discussed previously, the air phase within soil samples at the wet side of the LOO is discontinuous, suction contours on this part were developed based on the effective stress principle.

Fig. 5 shows the LWSBS of the soil developed by a combination of the constant stress contours in $e-p-e_{w}$ space.

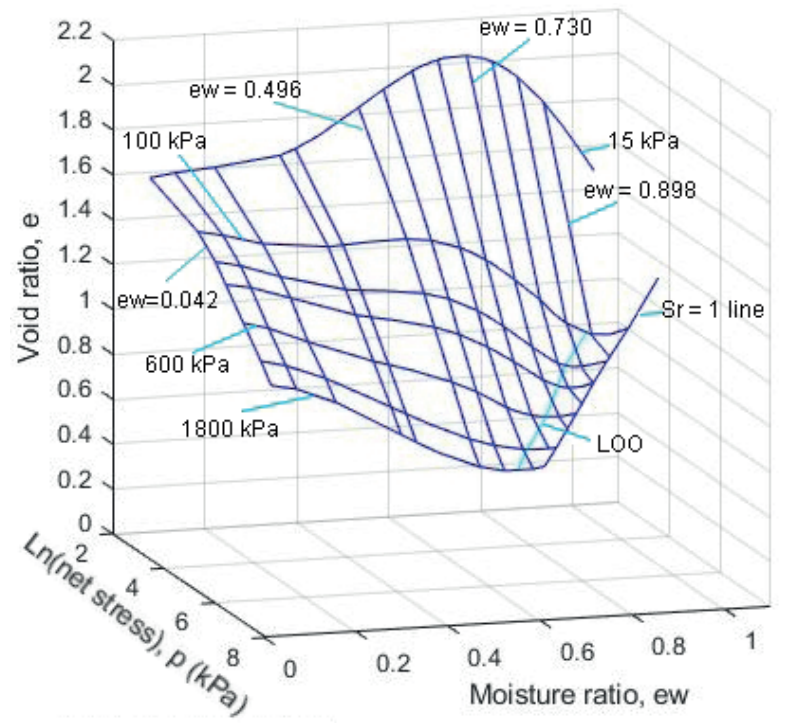

Fig. 5 LWSBS of soil used in $e-p-e_{w}$ space

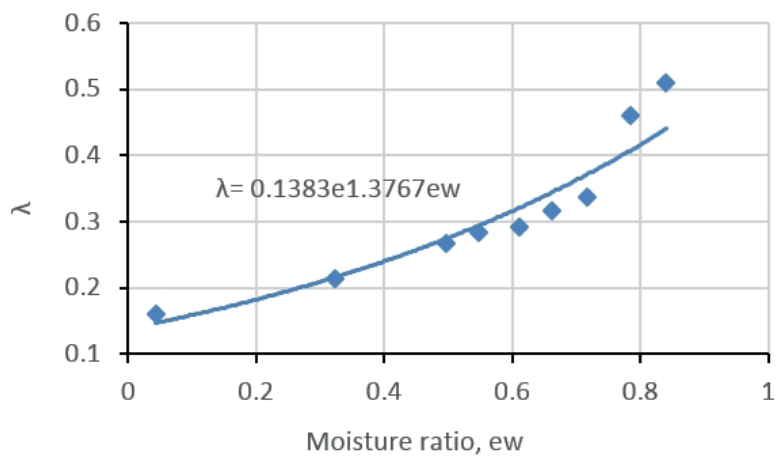

Fig. 6 Gradient of compression line $(\lambda)$ and moisture ratio relationship

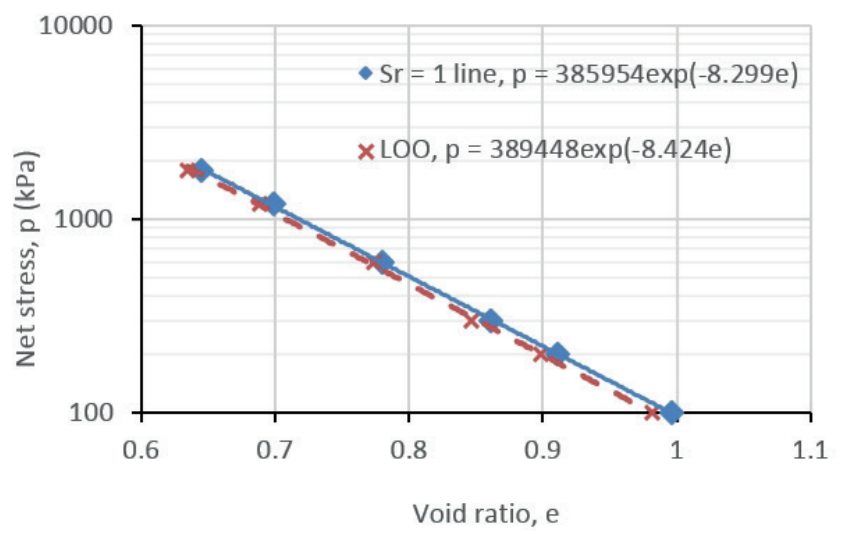

Fig. 7 The $S_{r}=1$ line and the LOO on the $p-e$ plane 
From the resulted constant suction contours, the suction values at different points on the parts of the constant net stress curves lying on the wet side of the LOO were determined and subsequently, these results were used to develop the complete SWCC for each compacted stress value. The constant suction contour at the dry side of the LOO will be developed according to the SWCCs. By analysing the data reported in previous studies Islam [10] presented that constant suction contours start from the dry side of LOO move across the LOO into the wet part and finally head toward the origin of the $e_{w}-e$ coordinate. Those contours are almost parallel to the $S_{r}=1$ line.

\subsubsection{Soil suction at the wet side of the LOO}

Soil suction at the wet side of LOO was correlated with the void ratio and moisture ratio of soil by considering the effective stress model, which is presented in Eq. (1), where the effective stress $p^{\prime}$ is defined as $p+S_{r} s$, and the slope $\lambda$ is a function of moisture ratio $\left(e_{w}\right)$. Equation (1) can be rewritten as:

$$
v=N-\lambda_{e_{w}} \ln \left(p+S_{r} s\right)
$$

As discussed in the previous part, the slope $\lambda_{e_{w}}$ is constant for constant moisture content compression curve, and $\lambda_{e_{w}}$ of different compression curves increase with increasing moisture content, as shown in Fig. 4. The relationship between $\lambda_{e_{w}}$ and $e_{w}$ was illustrated in Fig. 6 and can be presented by the following equation:

$$
\lambda_{e_{w}}=0.1382 e^{1.3787 e_{w}}
$$

Table 2 Suction values on the LOO

\begin{tabular}{lccccc}
\hline Point & $p(\mathrm{kPa})$ & $e_{w}$ & $e$ & $\lambda$ & $s$ \\
\hline A & 100 & 0.873 & 0.981 & 0.461 & 138 \\
C & 200 & 0.800 & 0.899 & 0.416 & 234 \\
D & 300 & 0.754 & 0.848 & 0.391 & 333 \\
E & 600 & 0.689 & 0.774 & 0.357 & 482 \\
F & 1200 & 0.613 & 0.689 & 0.322 & 827 \\
G & 1800 & 0.564 & 0.634 & 0.301 & 1264 \\
\hline
\end{tabular}

Considering two point $A$ and $B$ on the constant moisture content compression curve, the gradient is constant and the relationship between the void ratios at the two points can be written adopting Eq. (3):

$$
e_{A}-e_{B}=\lambda_{e_{w}} \ln \left(\frac{p_{B}+S_{r}^{B} s_{B}}{p_{A}+S_{r}^{A} s_{A}}\right)
$$

where $e_{A}, e_{B}$ and $p_{A}, p_{B}$ are the void ratio and net stress at point A and B, respectively; $S_{r}^{A}, S_{r}^{B}$ and $S_{A}, S_{B}$ are the degree of saturation and suction values at point $\mathrm{A}$ and point $\mathrm{B}$.

When $B$ is a point on the $S_{r}=1$ line (Fig. 8), $S_{r}{ }^{B}=1$ and $S_{B}=0$, and then the suction value at an arbitrary point $A$ on the wet side of the LOO can be computed as:

$$
S_{A}=\frac{1}{S_{r}^{A}}\left[\frac{p_{B}}{\exp \left(\frac{e_{A}-e_{B}}{\lambda_{e_{w}}}\right)}-p_{A}\right]
$$

where the degree of saturation at point $A$ can be calculated as $S_{r}^{A}=e_{w}{ }^{A} / e^{A}$, where $e_{w}{ }^{A}$ and $e^{A}$ are the moisture ration and the void ratio at point $A ; p_{A}$ was determined based upon constant net stress contours; $p_{B}$ was calculated from the $S_{r}=1$ line on the $p-e$ plane. The $S_{r}=1$ line, as shown in Fig. 7, was obtained from the saturated normal consolidation line, which can be presented as:

$$
p=38594 \exp (-8.299 e)
$$

The LOO was drawn in Fig. 8 based on the intersection point between the constant net stress contours and the LOO which is determined along the line of $S_{r}=0.89$. The equation for the LOO is as follows:

$$
p=389448 \exp (-8.424 e)
$$

The value of suction at any point on the wet side of LOO was calculated by using equation (5). Table 2 presents the values at the intersection points between the constant stress contours and the LOO in term of moisture content $\left(e_{w}\right)$, void ratio $(e)$, net stress $(p)$, compressibility $(\lambda)$, and the suction value $(s)$.

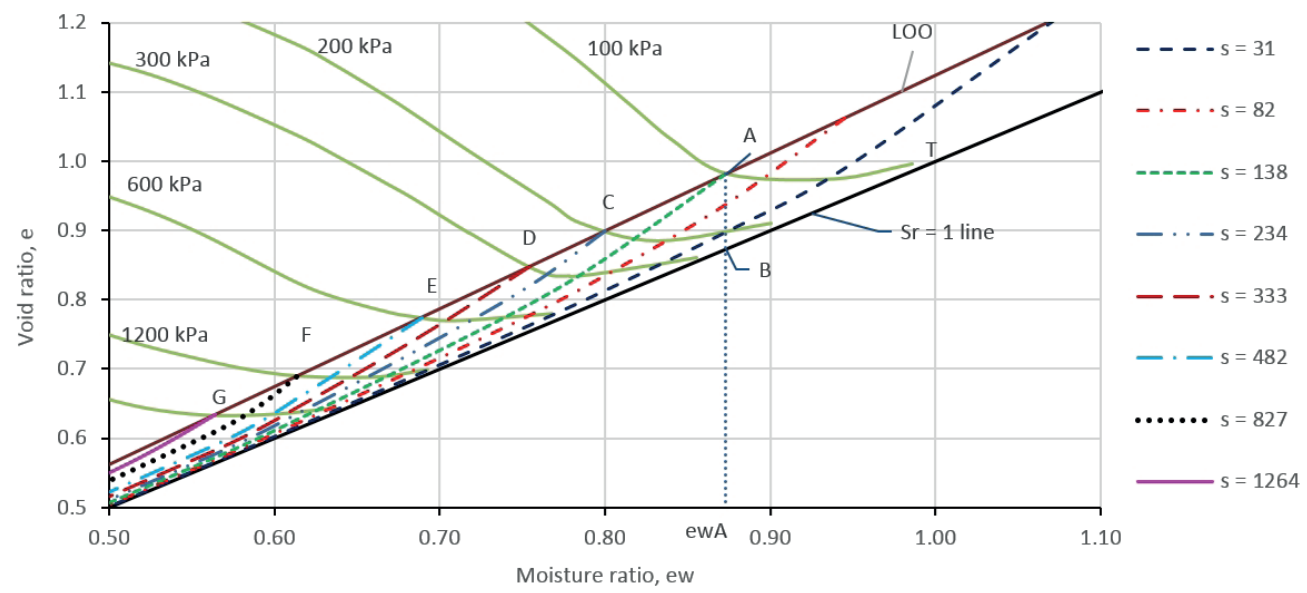

Fig. 8 Suction contours at the wet side of the LOO 


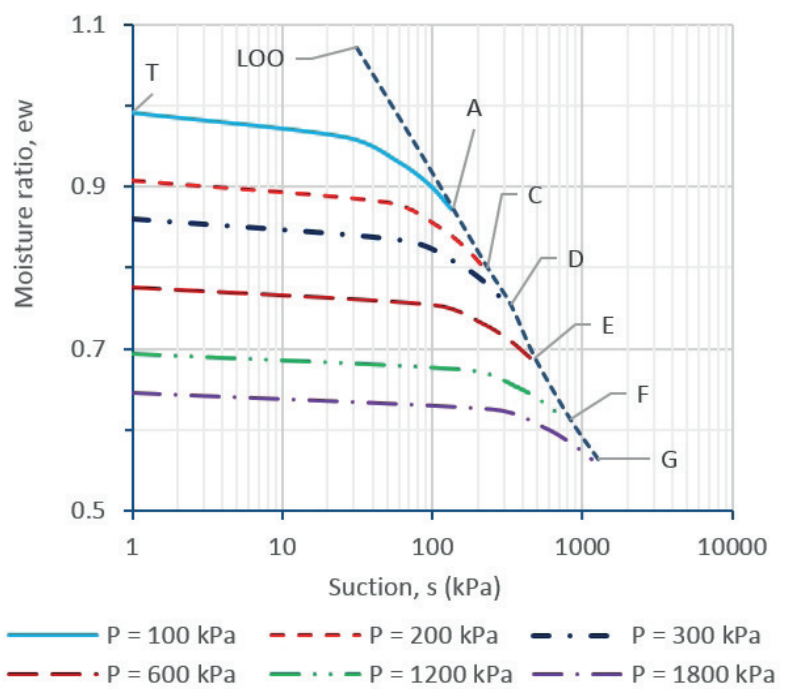

Fig. 9 Suction value on the part of constant stress curves lying at the wet side of the LOO

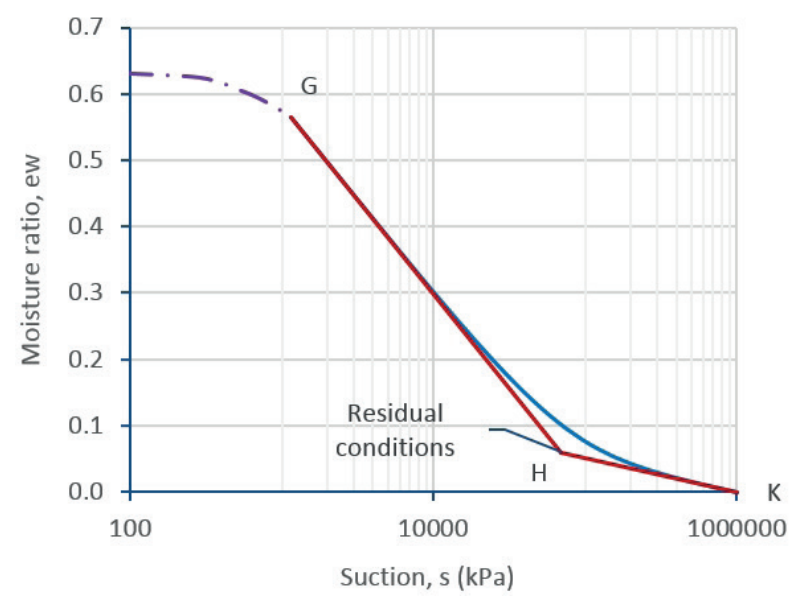

Fig. 10 Using Bézier curve to extend SWCC

The constant suction contours are shown in Fig. 8. It can be seen in Table 2 and Fig. 8 that the suction values on the LOO decrease with increasing moisture content and suction contours move from a specific point on the LOO towards the origin of the $e-e_{w}$ coordinate.

\subsubsection{Soil suction at the dry side of the LOO}

Suction value at different points on the part of constant stress curves lying at the wet side of the LOO (e.g. segment AT in Fig. 8) were determined and the suction - moisture ratio correlation was presented in Fig. 9.

It is well known that a typical SWCC consists of three distinct zones: the boundary effect zone, the transition zone, and the residual zone. During compaction the degree of saturation increase with increasing applied stress (or decreasing void ratio) so these SWCCs can be considered as wetting curves; the suction values at different points on the part of constant stress curves lying at the wet side of the LOO can be considered as the suction values of the points on SWCCs at the boundary effect zone. It is clear in Fig. 9 that the distribution of soil suction on the constant stress curves on the wet side of the LOO follows the shape of the part of SWCC at the boundary effect zone and it is capable to extend beyond the LOO for the dry side. In this study, the extension of SWCC from the wet side to the upper limit of soil suction $\left(10^{6} \mathrm{kPa}\right)$ was performed by using cubic Bézier curves, as proposed by Islam [10]. The variation of the moisture ratio and the suction through the transition and residual zone are presented by the two cubic Bézier curves, as follows:

$$
\begin{gathered}
e_{w}(t)=(1-t)^{3} e_{w 0}+3(1-t)^{2} t e_{w 1}+3(1-t) t^{2} e_{w 2}+t^{3} e_{w 3} \\
t \in[0,1] \\
\lg [s(t)]=(1-t)^{3} \operatorname{lgs}_{0}+3(1-t)^{2} t \lg s_{1}+3(1-t) t^{2} l g s_{2} \\
+t^{3} \lg s_{3} ; \quad t \in[0,1]
\end{gathered}
$$

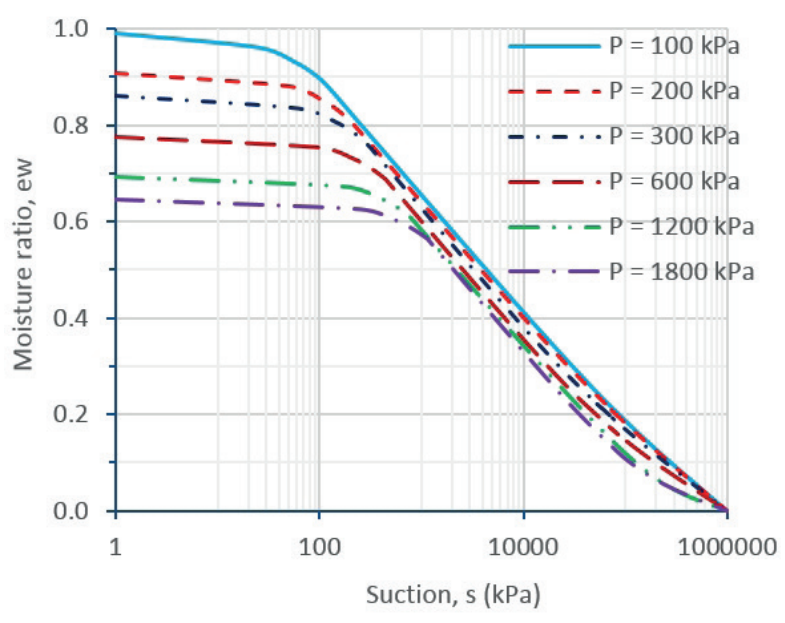

Fig. 11 Complete SWCCs for different net stresses

Table 3 Residual conditions applied in the study

\begin{tabular}{lcc}
\hline$p(\mathrm{kPa})$ & $e_{w r}$ & $S_{r}(\mathrm{kPa})$ \\
\hline 100 & $22.00 \%$ & 60,000 \\
200 & $23.00 \%$ & 50,000 \\
300 & $24.00 \%$ & 35,000 \\
600 & $18.00 \%$ & 50,000 \\
1200 & $6.00 \%$ & 150,000 \\
1800 & $8.00 \%$ & 100,000 \\
\hline
\end{tabular}

In Eq. (10), the logarithm with base 10 of suction was used because the suction and then the cubic Bézier curve is presented in the logarithm with base 10 scale. Fig. 10 shows the use of the cubic Bézier curves for extension of the SWCC for the 1800 $\mathrm{kPa}$ stress curve. In the cubic Bézier curve, the first control point is point $G$ on the $\mathrm{LOO}$ and the last control point is point $K$ at the upper limit of soil suction (i.e. $e_{w}=0$ and $s=10^{6} \mathrm{kPa}$ ), while point $H$ stands for the two middle control points. The coordinate values of point $H$ are the residual values of moisture content and suction. By that way, Eq. (9) was applied for the variation of moisture content and Eq. (10) was used to present the corresponding suction value with the values of coefficients are as follows: $e_{w 0}=e_{w G} ; e_{w 1}=e_{w 2}=e_{w H} ; e_{w 3}=e_{w K} ; \lg s_{0}=\lg S_{G}$; 
$l g s_{1}=\lg S_{2}=\lg s_{H} ; \lg s_{3}=\lg 10^{6}=6$. The complete SWCCs for different net stress are shown in Fig. 11. The value of the suction at any point on a constant stress curves at the dry side of the LOO can be computed by using the SWCC corresponding to the net stress value. The resulted suction contours at the dry side were joined with the parts on the wet side and the complete contour for the whole LWSBS are presented in Fig. 12.
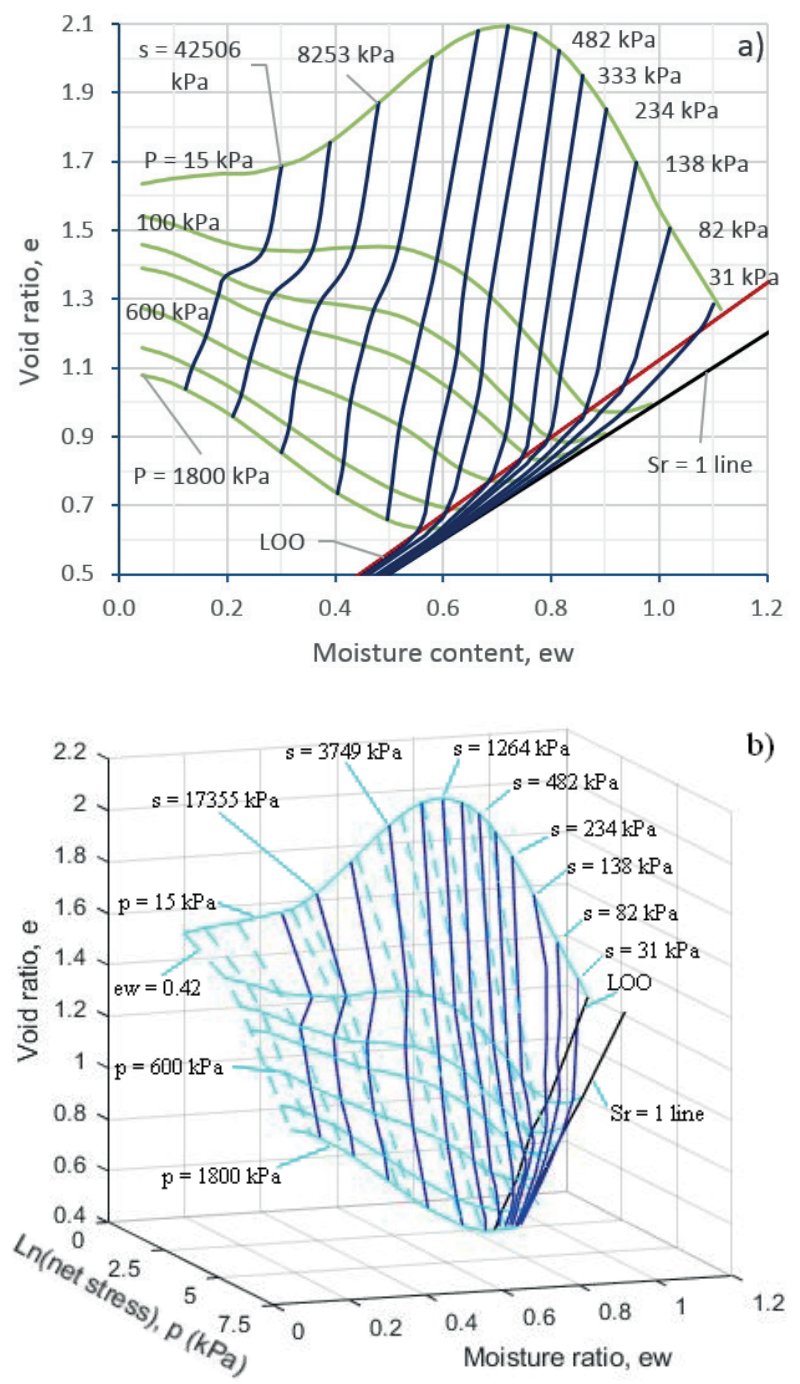

Fig. 12 The complete suction contours on the LWSBS:

(a) in the $e-e_{w}$ plane; (b) in the $e-e_{w}-p$ space

It can be seen in Fig. 12 that the value of suction on a constant stress contour decreases with increasing moistures content. Considering soil samples compacted with constant moisture content, soil suction increase with increasing applied stress on the LWSBS. Suction contours at the dry side of the LOO converge towards the LOO and intersect constant net stress curves at some angle, in some cases close to a right angle. After moving across the LOO, suction contours at the wet side of the LOO head toward the origin of the $e-e_{w}$ plane. This result is in accordance with the observation in Kodikara's [1] analysis using the data reported by Tarantino and De Col [8] and some others. It is noted here that the suction value at the dry side of the LOO is dependent on the values of suction $\left(S_{r}\right)$ and moisture contents $\left(e_{w r}\right)$ at the residual conditions (at point $\mathrm{H}$ in Fig. 10). The results in this study were generated after a trial process with the residual suction and moisture content shown in Table 3. This demands further experiments which can measure directly the suction inside the specimen to complete the model.

\section{Conclusions}

This study presents the results of compaction process under static load at different moisture contents for an unsaturated soil in Hungary. The LWSBS in the MPK framework illustrates the direct relationship between the volume of soil (dry density/ or void ratio) with the moisture content and the applied stress. The soil suction was incorporated in the LWSBS. The results showed that the value of suction on a constant stress contour decreases with increasing moistures content. Suction contours at the dry side of the LOO converge towards the LOO and intersect constant net stress curves at some angle, in some cases close to a right angle. After moving across the LOO, suction contours at the wet side of the LOO head toward the origin of the $e-e_{w}$ plane. This result is in accordance with the trend of the variation of suction presented in the literature. Since the MPK framework has been validated in term of presenting the volumetric behaviour of compacted unsaturated soils, with the incorporation of suction on the LWSBS, it is expected to be capable of explaining unsaturated soil behaviour in general including shearing and tensile behaviour of unsaturated soil. Further studies on the effects of the degree of saturation on the behaviour of compacted soils such as the works of Vásárhelyi and Gálos [14], and Yilmaz et al. [15] are also expected to be interpreted in $e-\mathrm{p}-e_{w}$ space.

\section{References}

[1] Kodikara, J. "New framework for volumetric constitutive behaviour of compacted unsaturated soils". Canadian Geotechnical Journal, 49(11), pp. 1227-1243. 2012. 10.1139/t2012-084

[2] Alonso, E. E., Gens, A., Josa, A. "A constitutive model for partially saturated soils". Géotechnique, 40(3), pp. 405-430. 1990. 10.1680/ geot.1990.40.3.405

[3] Wheeler, S. J., Sivakumar, V. "An elasto-plastic critical state framework for unsaturated soil". Géotechnique, 45(1), pp. 35-53. 1995. 10.1680/ geot.1995.45.1.35

[4] Sivakumar, V., Wheeler, S. J. "Influence of compaction procedure on the mechanical behaviour of an unsaturated compacted clay. Part 1: Wetting and isotropic compression". Géotechnique, 50(4), pp. 359-368. 2000. 10.1680/geot.2000.50.4.359

[5] Wheeler, S. J., Sharma, R. S., Buisson, M. S. R. "Coupling of hydraulic hysteresis and stress-strain behavior in unsaturated soils". Géotechnique, 53(1), pp. 41-54. 2003. 10.1680/geot.2003.53.1.41

[6] Gallipoli, D., Gens, A., Sharma, R., Vaunat, J. "An elasto-plastic model for unsaturated soil incorporating the effects of suction and degree of saturation on mechanical behaviour". Géotechnique, 53(1), pp. 123-135. 2003. 10.1680/geot.2003.53.1.123 
[7] Thu, T. M., Rahardjo, H., Leong, E.-C. "Elastoplastic model for unsaturated soil with incorporation of the soil-water characteristic curve". Canadian Geotechnical Journal, 44(1), pp. 67-77. 2007. 10.1139/t06-091

[8] Tarantino, A., De Col, E. "Compaction behaviour of clay". Géotechnique, 58(3), pp. 199-213. 2008. 10.1680/geot.2008.58.3.199

[9] Sheng, D., Fredlund, D. G., Gens, A. "A new modelling approach for unsaturated soils using independent stress variables". Canadian Geotechnical Journal, 45(4), pp. 511-534. 2008. 10.1139/T07-112

[10] Islam, T. A study of volumetric behaviour of compacted clayey soils in the void ratio, moisture ratio and net stress space. Thesis, Monash University, Australia. 2015. 10.4225/03/58b61cbf82156

[11] Sheng, D. "Constitutive modelling of unsaturated soils: Discussion of fundamental principles". General Report presented at the 5th International Conference on Unsaturated Soils. In: Unsaturated soils. (Alonso, E. E., Gens, A. (Eds.)). CRC Press, Taylor \& Francis Group. Vol. 1, pp. 91-122. 2010 .
[12] Bishop, A.W., "The principle of effective stress". Tecknisk Ukebald, 106(39), pp. 859_863. 1959.

[13] Nagy, G., Nagy, L., Kopecskó, K. "Examination of the Physico-chemical Composition of Dispersive Soils". Periodica Polytechnica Civil Engineering, 60(2), pp. 269-279, 2016. 10.3311/PPci.8896

[14] Vásárhelyi, B., Gálos, M. "How does the water saturation influence the mechanical properties of the volcanic tuffs". Periodica Polytechnica Civil Engineering, 48(1-2), pp. 65-72, 2004. https://pp.bme.hu/ci/article/ view/583

[15] Yilmaz, Y., Kheirjouy, A. B., Akgungor, A. P. "Investigation of the Effect of Different Saturation Methods on the Undrained Shear Strength of a Clayey Soil Compacted with Standard and Modified Proctor Energies". Periodica Polytechnica Civil Engineering, 60(3), pp. 323-329, 2016. 10.3311/PPci.8891 